\title{
Increasing a Robust Antigen-Specific Cytotoxic T Lymphocyte Response by FMDV DNA Vaccination with IL-9 Expressing Construct
}

\author{
Qiang Zou, Bing Wu, Xiaodan He, Yizhi Zhang, Youmin Kang, Jin Jin, Hanqian Xu, \\ Hu Liu, and Bin Wang
}

State Key Laboratory for Agro-Biotechnology, Department of Microbiology and Immunology, College of Biological Science, China Agricultural University, Beijing 100193, China

Correspondence should be addressed to Bin Wang, bwang3@cau.edu.cn

Received 30 November 2009; Accepted 6 February 2010

Academic Editor: Hanchun Yang

Copyright ( 2010 Qiang Zou et al. This is an open access article distributed under the Creative Commons Attribution License, which permits unrestricted use, distribution, and reproduction in any medium, provided the original work is properly cited.

\begin{abstract}
Various chemokines and cytokines as adjuvants can be used to improve efficacy of DNA vaccination. In this study, we sought to investigate if a DNA construct expressing IL-9 (designed as proV-IL9) as a molecular adjuvant enhance antigen specific immune responses elicited by the $\mathrm{pcD}-\mathrm{VP} 1 \mathrm{DNA}$ vaccination. Mice immunized with pcD-VP1 combined with proV-IL9 developed a strong humoral response. In addition, the coinoculation induced significant higher level of antigen-specific cell proliferation and cytotoxic response. This agreed well with higher expression level of IFN- $\gamma$ and perforin in CD8 ${ }^{+} \mathrm{T}$ cells, but not with IL-17 in these T cells. The results indicate that IL-9 induces the development of IFN- $\gamma$-producing CD8 ${ }^{+} \mathrm{T}$ cells (Tc1), but not the IL-17-producing $\mathrm{CD}^{+} \mathrm{T}$ cells (Tc17). Up-regulated expressions of BCL-2 and BCL-XL were exhibited in these Tc1 cells, suggesting that IL-9 may trigger antiapoptosis mechanism in these cells. Together, these results demonstrated that IL- 9 used as molecular adjuvant could enhance the immunogenicity of DNA vaccination, in augmenting humoral and cellular responses and particularly promoting Tc1 activations. Thus, the IL-9 may be utilized as a potent Tc1 adjuvant for DNA vaccines.
\end{abstract}

\section{Introduction}

Foot and mouth disease virus (FMDV) is a member of genus Aphthovirus in the family Picornaviridae and causes a great economical loss for farm animals [1]. Since the current available inactivated FMDV vaccine is still considered as a potential outbreak, alternative vaccination methods should be developed [2]. DNA vaccination offers one of such alternatives, which is a relatively novel and powerful method of immunization, capable of humoral as well as cellular immunity [3-6]. To date, various approaches have been developed to enhance the immunogenicity of plasmid DNA vaccines, such as the use of plasmid expressing cytokine as a molecular adjuvant $[7,8]$.

IL-9, a cytokine produced by $\mathrm{T}$ cells, mast cells, eosinophils, and neutrophils, stimulates cell proliferation and prevents apoptosis [9]. In addition, IL-9 supports the growth of $\mathrm{T}$ cells and also increases the production of
IL-6 in B lymphocytes in a phenomenon culminating in an enhancement of IgE or IgG1 synthesis [10, 11]. IL-9 producing-DC can be used to induce protective immune response against intestinal nematodes [12].

In spite of its immune effects, IL-9 or its expressing construct has not been examined to determine if it can be used as adjuvant, directly affecting elicited immune responses of vaccines. In this study, we demonstrated that coinoculation of the IL-9 expressing construct with VP1 DNA vaccine, encoding VP1 capsid protein of foot-andmouth disease virus, induced strong humoral and cellular immune responses, including the antigen-specific CD8 Tc1 activation.

\section{Materials and Methods}

2.1. Reagents and Animals. FMDV VP1 peptide representing the T-cell epitope (aa133-147, SSKYGDTSTNNVRGD) was 
TABLE 1: Immunization groups.

\begin{tabular}{ccc}
\hline Groups & DNA vaccine & Adjuvant \\
\hline 1 & Naïve & $100 \mu \mathrm{g}$ proV \\
2 & $100 \mu \mathrm{g} \mathrm{pcD}$ & $100 \mu \mathrm{g}$ proV-IL9 \\
3 & $100 \mu \mathrm{g} \mathrm{pcD}$ & $100 \mu \mathrm{g}$ proV \\
4 & $100 \mu \mathrm{g} \mathrm{pcD}-\mathrm{VP} 1$ & $100 \mu \mathrm{g}$ proV-IL9 \\
5
\end{tabular}

Note: pcD and proV are empty vectors.

synthesized by GL Biochem Co., Ltd. (Shanghai, China). Conjugated Abs used for flow cytometry analysis were purchased from BD Pharmingen (San Diego, USA). Adult female C57BL/6 mice at 8-10 weeks of age were purchased from Animal Institute of Chinese Medical Academy (Beijing, China) and feed with pathogen-free food and water in a 12-h light-cycle.

2.2. Plasmid Construction and Preparations. The pcD-VP1 was constructed into pcDNA3.0 as described previously [13]. The coding sequence for mouse IL-9 was obtained from mRNA isolated from spleens by RT-PCR method and subcloned into the proVAX vector [14] to designate as proV-IL9. The plasmids were maxi-prepared by the alkaline method, subsequently purified by Qiagen Maxi prep kit (Qiagen Inc., Duesseldorf, Germany), and diluted in saline solution.

2.3. Transfection of the BHK Cell Lines. The purified plasmids proV-IL9 were transfected into BHK cells with Lipofectamine according to the manufacturer's instructions (Invitrogen, CA, USA). The transfected cells were harvested after $48 \mathrm{~h}$ and blocked with Fc-Block (BD Phamingen) in PBS for $30 \mathrm{~min}$ at $4^{\circ} \mathrm{C}$ before fixed with $4 \%$ paraformaldehyde and permeabilized with saponin. Cells were intracellularly stained with anti-IL-9-PE (BD Phamingen) for 1 hour at $4^{\circ} \mathrm{C}$ and analyzed with as FACScalibur using the Cell Quest Pro Software (BD Bioscience).

2.4. Immunization. The $\mathrm{C} 57 \mathrm{BL} / 6$ mice were randomly divided into five groups (6 per group), and immunized intramuscularly on days 0,14 , and 28 listed in Table 1 .

2.5. Detection of Anti-VP1-Specific Antibodies. The detection of anti-VP1-specific antibodies in the sera was carried out by quantitative ELISA assays as previously described [15]. The sera from immunized mice were tested individually on day 7 after the third immunization, and the concentrations calculated were the means of three independent assays.

2.6. Cell Proliferation. Single lymphocyte suspensions were obtained from spleens of the mice on day 7 after the third immunization. Cells in RPMI-1640 medium (Gibco, Eggenstein, Germany)/10\% FBS were used to perform the cell proliferation by MTT method after the GST-VP1 stimulation in vitro for $48 \mathrm{~h}$. This method was according to the previously described protocols [15]. The OD values were read at $490 \mathrm{~nm}$ by a plate reader (Magellan, Tecan Austria GmbH). Data were expressed as stimulation index (SI), calculated as the mean reading of triplicate wells stimulated with an antigen, divided by the mean reading of triplicate wells stimulated with the medium.

2.7. In Vivo Cytotoxic Assay. In vivo cytotoxic assay was performed as described previously [14] with the use of splenocytes from naïve C57BL/6 mice pulsed with $10^{-6} \mathrm{M}$ VP1 peptide and labeled with a high concentration of CFSE (15 $\mu \mathrm{M}, \mathrm{CFSE}^{\text {high }}$ cells) as target cells. A portion of the same splenocytes was labeled with a low concentration of CFSE $\left(0.5 \mu \mathrm{M}, \mathrm{CFSE}^{\text {low }}\right.$ cells $)$ without peptide pulse as a nontarget control. The target and control cells were mixed in a $1: 1$ ratio and injected into immunized mice at $2 \times 10^{7}$ total cells per mouse via the tail vein on day 7 after the third immunization. Four hours later, lymphnodes and the spleens of injected mice were removed and the target and control cells were analyzed by their differential CFSE fluorescent intensities using an FACSCalibur (BD Biosciences, USA). Specific lysis was calculated using the following formula: ratio $=$ percentage $\mathrm{CFSE}^{\text {low }} /$ percentage $\mathrm{CFSE}^{\text {high }}$. Percentage specific lysis $=[1-($ ratio unprimed $/$ ratio primed $) \times 100]$.

2.8. Flow Cytometric Analysis. Splenic T cells were isolated on day 7 after the third immunization. T cells or $\mathrm{CD}^{+} \mathrm{T}$ cells from splenocytes of C57/B6 mice isolated by MACS sorting (R\&D Systems, Inc., Huntingdon Valley, PA, USA) at $0.5 \times 10^{6}$ cells $/ 20 \mu \mathrm{L}$ were stimulated in 96-well plates with VP1 peptide $(5 \mu \mathrm{g} / \mathrm{mL})$ and anti-CD28 $(5 \mu \mathrm{g} / \mathrm{mL}) \mathrm{mAb}$ for $6 \mathrm{~h}$ at $37^{\circ} \mathrm{C}$ and $5 \% \mathrm{CO}_{2}$. Monensin $(2 \mu \mathrm{g} / \mathrm{mL})$ was added for the last $4 \mathrm{~h}$ and the cells were washed three times with PBS/10\%FCS. Cells were blocked with Fc-Block (BD Phamingen, San Diego, USA) in PBS for $30 \mathrm{~min}$ at $4^{\circ} \mathrm{C}$ before fixed with $4 \%$ paraformaldehyde and permeabilized with saponin, immunostained with isotype controls, or double stained with anti-CD8-FITC and anti-IFN- $\gamma$-PE, or antiCD8-FITC and anti-IL-17-PE, or anti-CD8-FITC and antiperforin-PE for $1 \mathrm{~h}$ at $4^{\circ} \mathrm{C}$. The cells were washed and analyzed with an FACScalibur using the Cell Quest Pro Software (BD Bioscience).

2.9. RT-PCR. Total RNA was extracted from total splenocytes or from sorted $\mathrm{CD}^{+} \mathrm{T}$ cells and then was reversetranscribed. Seven days after the third immunization, $\mathrm{CD} 8^{+}$ $\mathrm{T}$ cells from splenocytes of C57/B6 mice were isolated by MACS sorting (R\&D Systems,Inc). The sequences of the 


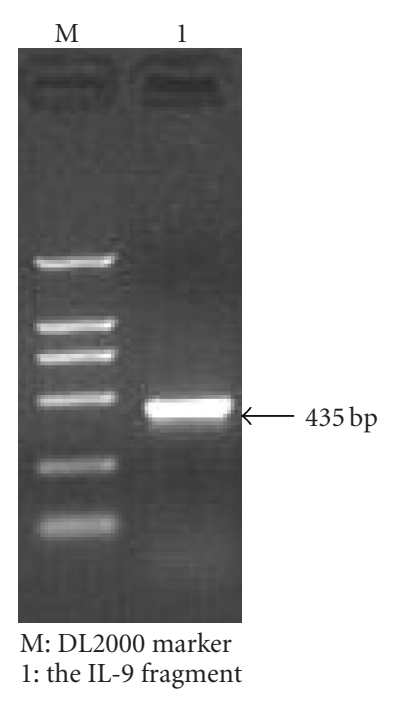

(a)

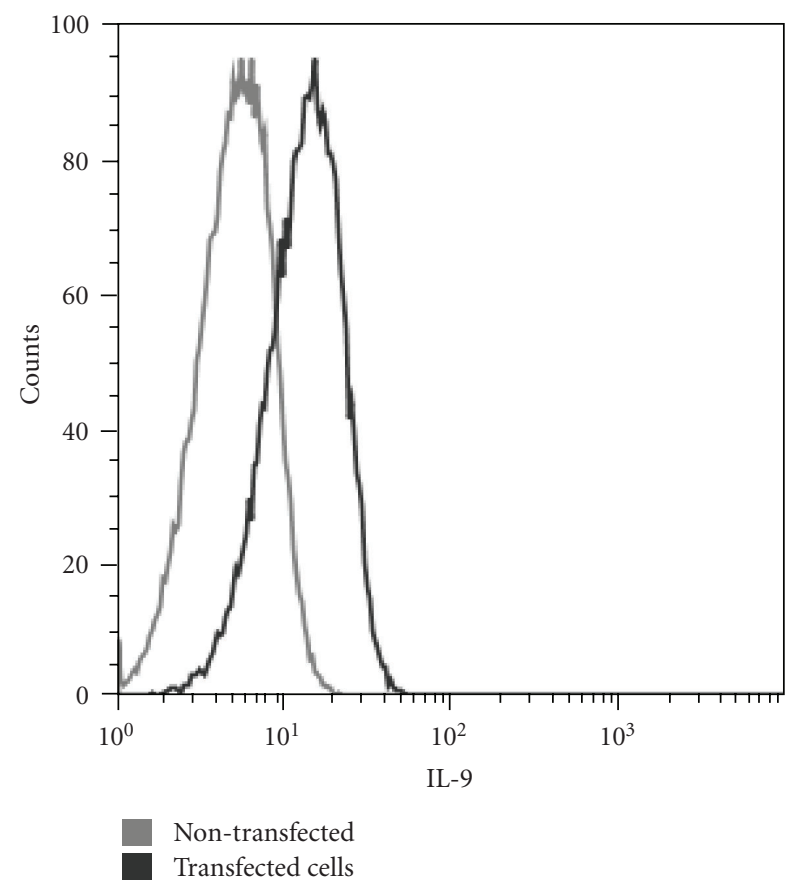

(b)

Figure 1: Cloning and expression of IL-9. (a) The coding sequence for mouse IL-9 was obtained from mRNA isolated from spleens. (b) BHK cells $48 \mathrm{~h}$ after the transfections with proV-IL9 and untransfected were collected, fixed, and intracellularly stained with anti-IL-9-PE. The results were analyzed by the FACScalibur.

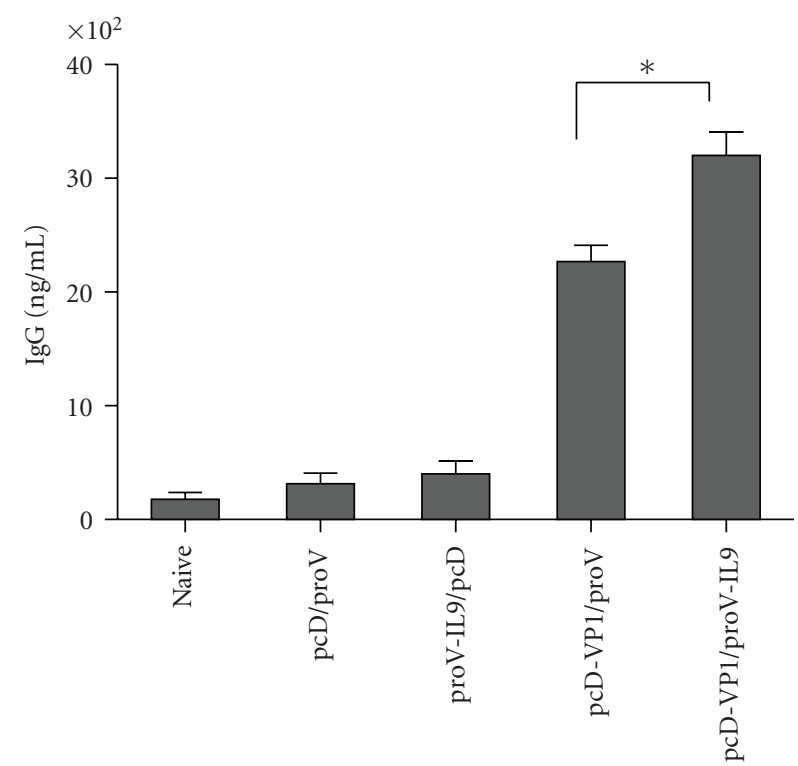

(a)

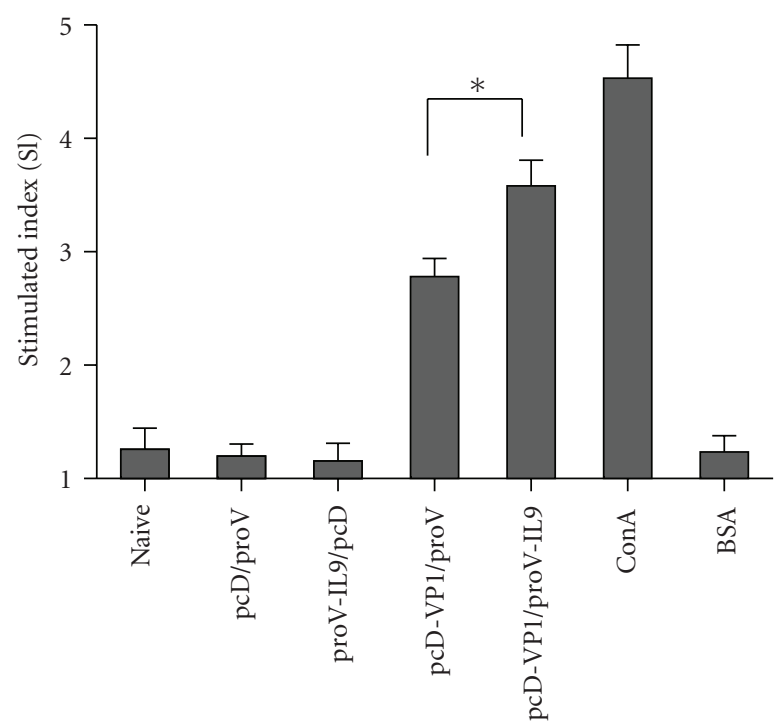

(b)

Figure 2: Effect of IL-9 as adjuvant on humoral and cell proliferative responses. (a) Serum samples from six mice per immunized group were analyzed for specific antibodies against VP1 by ELISA. Mouse IgG with a known concentration was serially diluted and a standard curve was obtained for concentration of specific binding. (b) T cells were isolated from mice (6 per group) of all groups on day 7 after the third immunization and stimulated with VP1 recombinant protein. A cell proliferation response was analyzed using MTT and expressed as stimulation index. Data showed are representatives from three independent experiments. ${ }^{*} P<.05$ compared with pcD-VP1 group. 

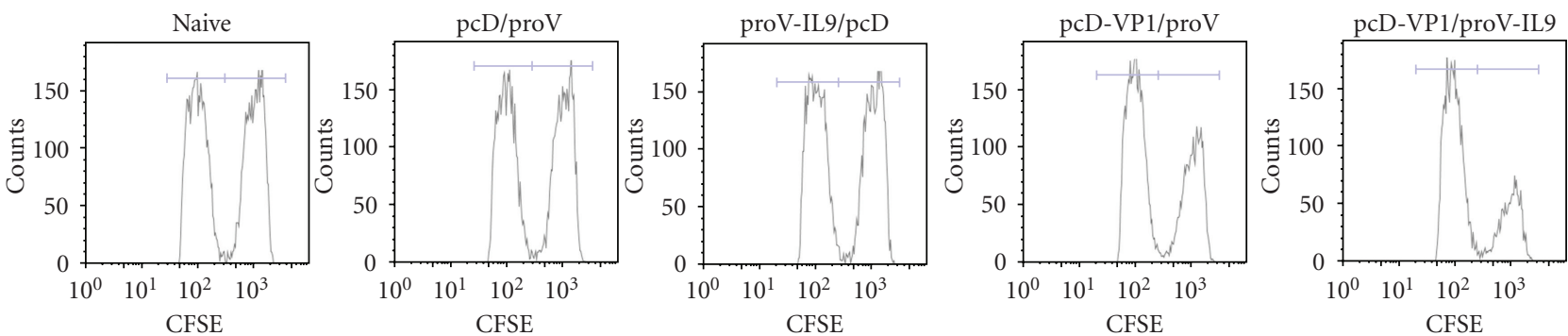

(a)

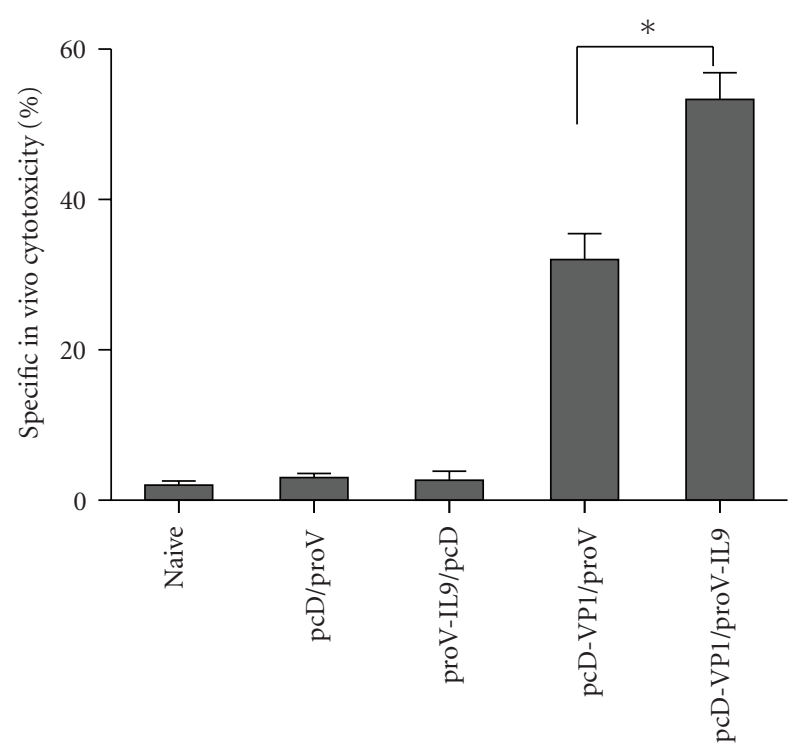

(b)

FIGURE 3: Effects of IL-9 on in vivo cytotoxic responses. (a) To analyze effect of IL-9 on VP1-specific cytotoxicity, the in vivo cytotoxic assay was performed by comparing the ratio of CSFE ${ }^{\text {high }}$ of target cells versus CSFE ${ }^{\text {low }}$ of controls after in vivo transfer into immunized mice by FACS. (b) The percentage of specific lysis is summarized in the means of the three independent experiments. ${ }^{* *}$ indicates $P<.01$ between groups.

primers are listed in Table 2. Samples were run by $1.5 \%$ agarose gel and visualized by staining with EtBr.

2.10. Statistical Analysis. Results are presented as means \pm S.E.M. Student's $t$-test analysis was used for data analysis. A value of $P<.05$ was considered to be statistically significant.

\section{Results}

3.1. Cloning for IL-9 and Expression in BHK Cells. To construct the IL-9 expression plasmid proV-IL9, the entire mouse IL- 9 cDNA (435 bp) was cloned, verified by sequencing, and subcloned into the proVAX vector for eukaryotic expression (Figure 1(a)). In order to confirm proV-IL9 protein expressing, transfected cells were used in intracellular staining analysis by the use of anti-IL-9-PE after $48 \mathrm{~h}$ of the transfection. Its eukaryotic expression was observed and showed in Figure 1(b).

3.2. IL-9 as a Molecular Adjuvant Enhances Humoral and Cell Proliferative Responses. To examine the effect of IL-9 on the humoral response in mice, serum total IgG antibodies against VP1 were determined by quantitative ELISA on day 7 after the third immunization. Compared to the group immunized with pcD-VP1 plus empty vector proV, a significantly enhanced level of the production of total IgG was found in the groups immunized with pcD-VP1 plus proVIL9 (Figure 2(a)). To determine whether IL-9 influences T cell-mediated immunity, lymphocytes isolated from the mice on day 7 after the third immunization were stimulated with GST-VP1 protein as the specific antigen, ConA as a positive control, BSA as a nonspecific control, and medium as a negative control. The highest level of cell proliferation responses was induced in the groups immunized with $\mathrm{pcD}$ VP1 plus proV-IL9 (Figure 2(b)). These data suggest that IL-9 as molecular adjuvant increased humoral and cell proliferative responses.

3.3. The Adjuvant Effect of IL-9 on Cytotoxicity. To examine whether proV-IL-9 could enhance antigen-specific cytotoxic response, in vivo cytotoxic assay was performed on day 7 

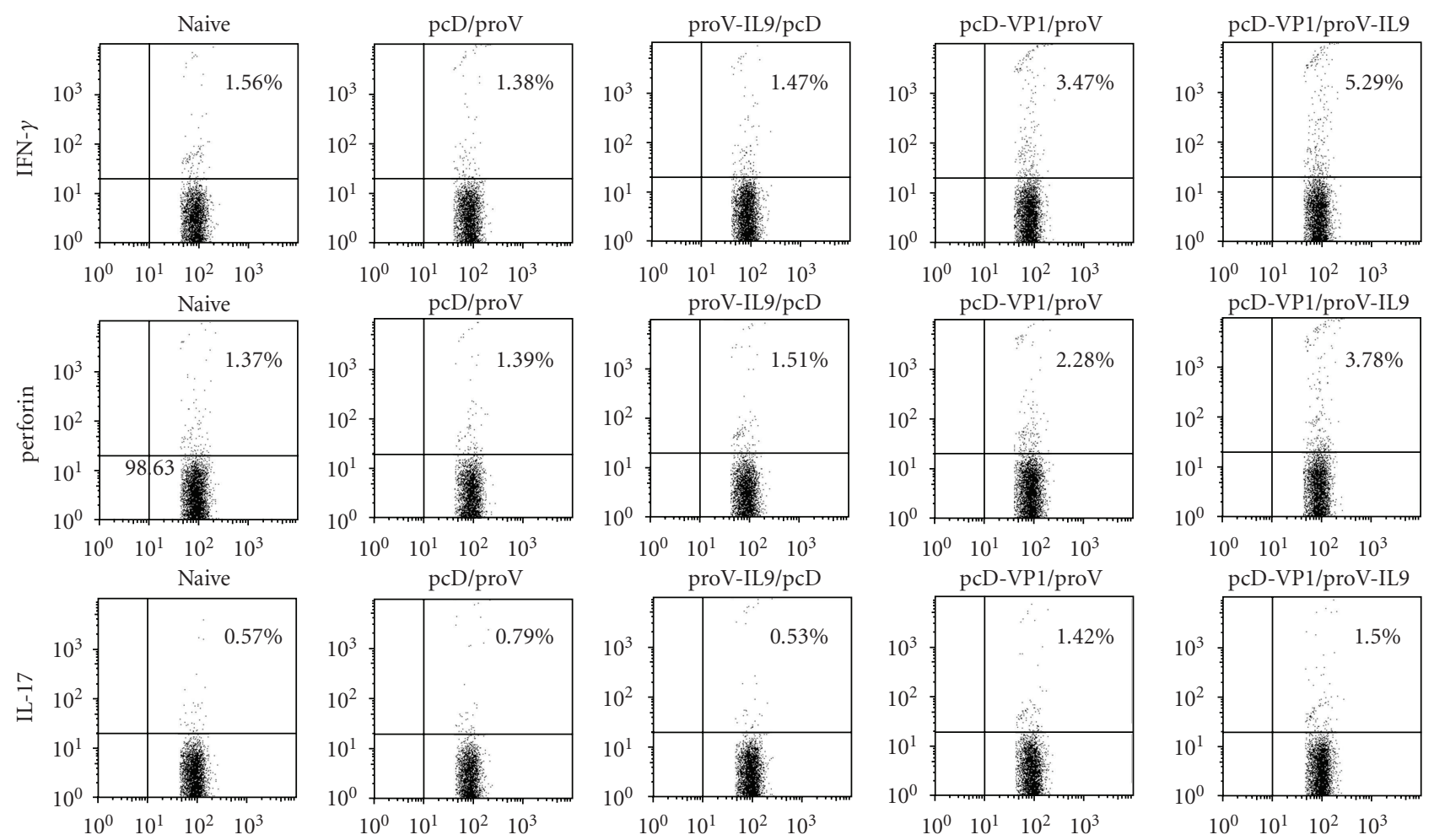

(a)
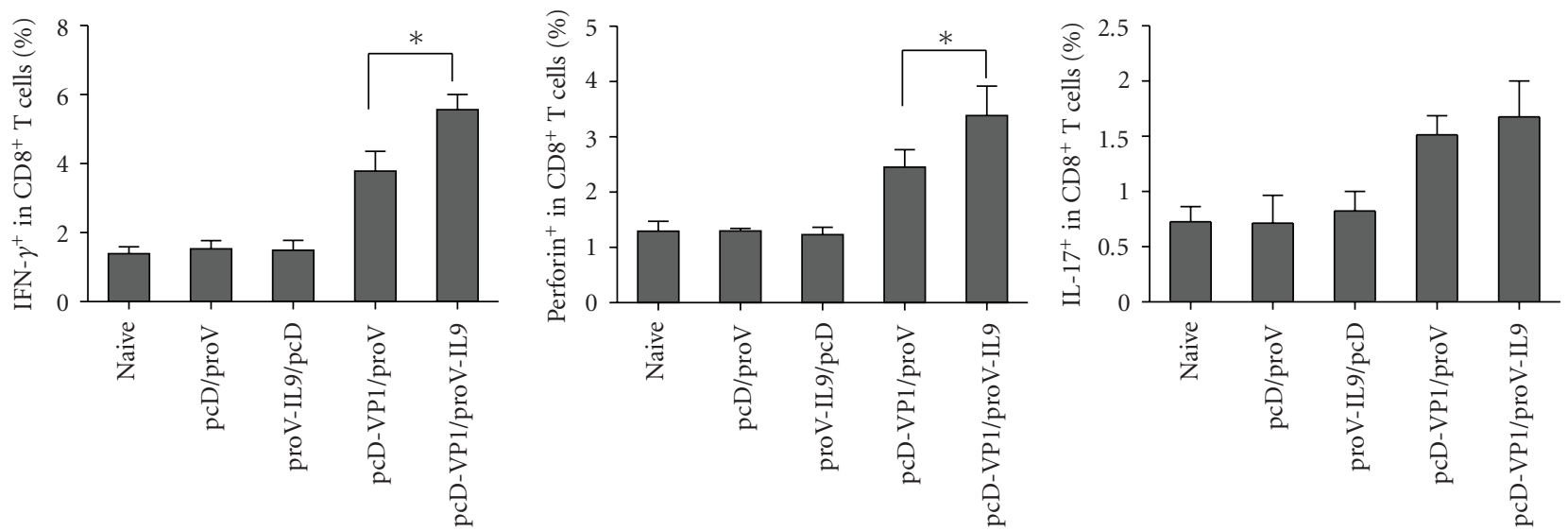

(b)

FIgURE 4: Analysis of antigen-specific cytokine productions in CD8 ${ }^{+} \mathrm{T}$ cells by FACS. (a) CD8 ${ }^{+} \mathrm{T}$ cells isolated from the spleen of C57BL/6 mice on day 7 after the final boost were stimulated with VP1 peptide for $4 \mathrm{~h}$ in culture. Intracellular staining for IFN- $\gamma$, perforin, and IL-17 in $\mathrm{CD}^{+} \mathrm{T}$ cells was performed. (b) The summaries of percentage were shown in the means of the three independent experiments.

after the third immunization. As shown in Figure 3, the highest percentage of antigen-specific lysis was approximately $56.3 \%$, from the mice immunized with pcD-VP1 plus proVIL9, whereas it was $38.2 \%$ from the mice immunized with pcD-VP1 plus proV.

3.4. Effect of IL-9 on Cytokine Expression in $C D 8^{+} T$ Cells. Since both IFN- $\gamma$-producing $\mathrm{CD}^{+} \mathrm{T}$ cells $(\mathrm{Tc} 1)$ and IL17-producing $\mathrm{CD}^{+} \mathrm{T}$ cells ( $\mathrm{Tc17}$ ) could enhance the cytotoxic responses $[16,17]$, we sought to determine which $\mathrm{CD}^{+} \mathrm{T}$ cells were affected by the IL-9. $\mathrm{CD}^{+} \mathrm{T}$ cells were purified before used to perform the intracellular stainings against IFN- $\gamma$, perforin, or IL-17 on day 7 after the third immunization. As a representative result shown in Figure 4(a)-4(b), the expression of antigen-induced IFN$\gamma$ and perforin in $\mathrm{CD}^{+} \mathrm{T}$ cells were significantly higher in the mice immunized with pcD-VP1 plus proV-IL9 than the other groups, whereas the percentage of IL-17 in CD8 ${ }^{+}$ $\mathrm{T}$ cells of mice immunized with pcD-VP1 plus proV-IL9 


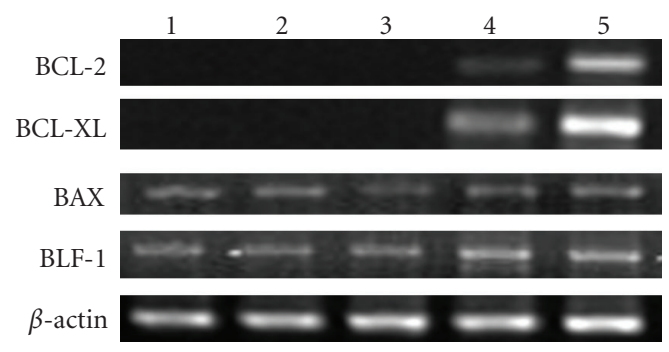

(a)

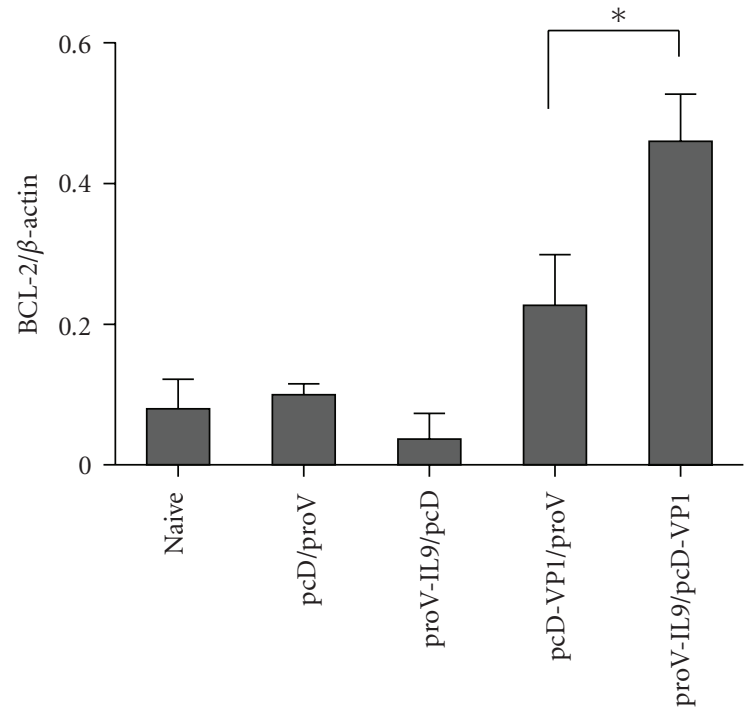

(b)

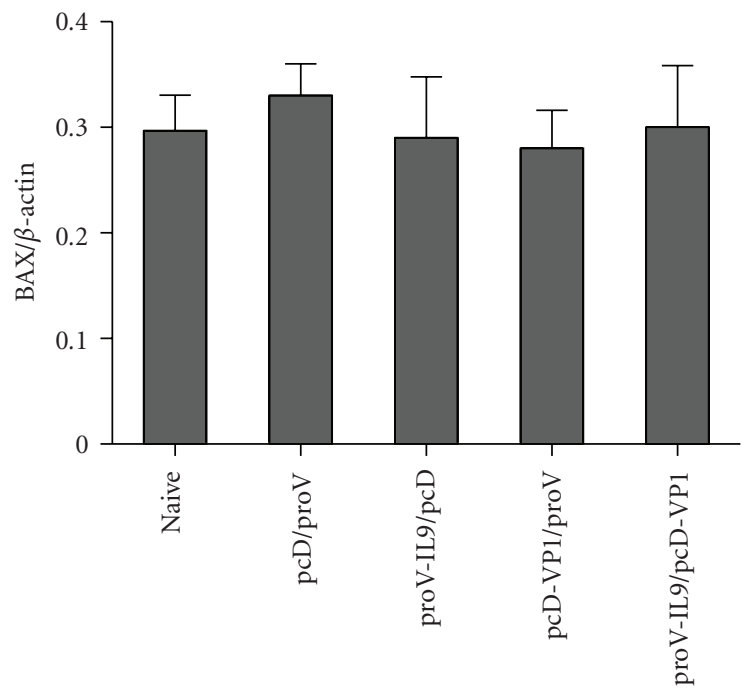

(d)

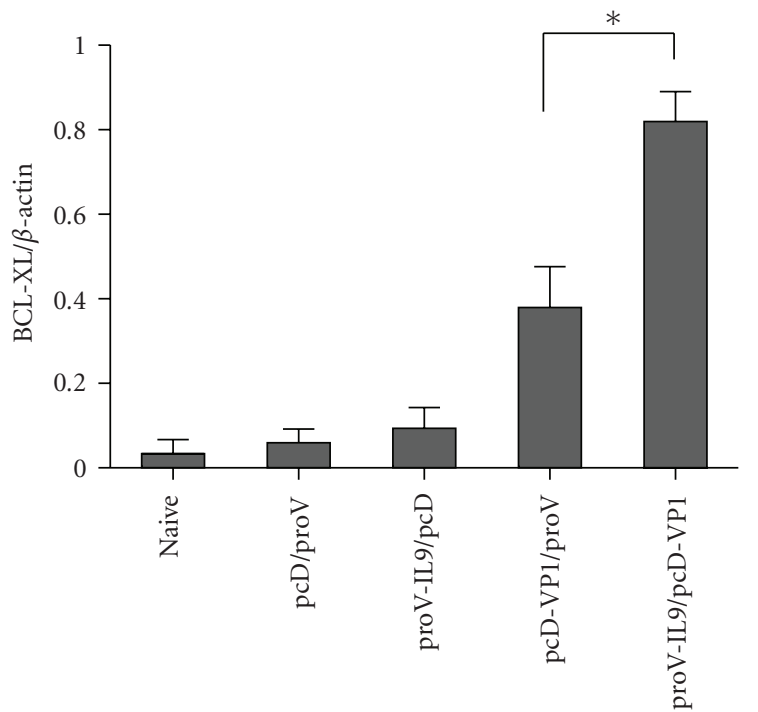

(c)

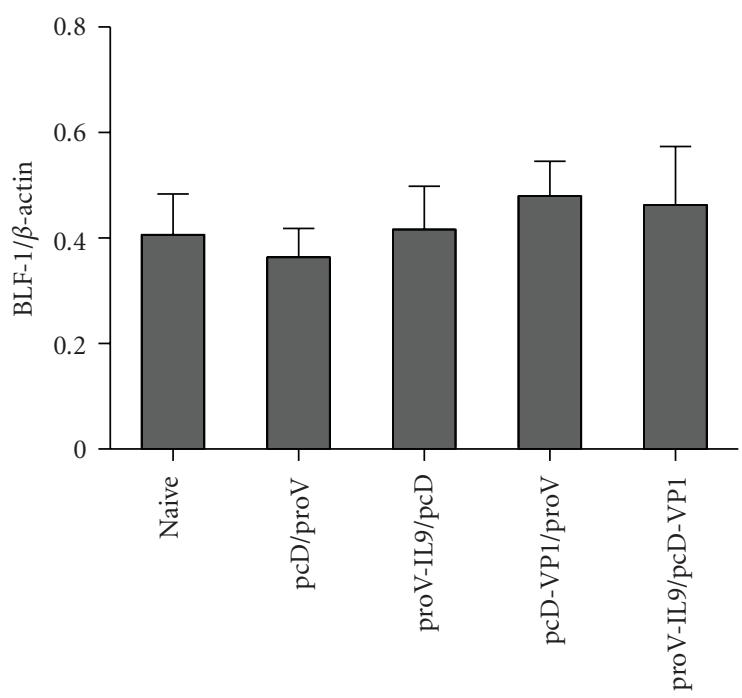

(e)

Figure 5: Expression of apoptotic or proapoptotic genes in $\mathrm{CD}^{+} \mathrm{T}$ cells by RT-PCR. Total RNA was isolated from the splenic CD8 ${ }^{+} \mathrm{T}$ cells of immunized on day 7 after final boost. (a) The expression levels of apoptotic or proapoptotic genes were semiquantitatively measured by RT-PCR through the normalization of the tested cDNA concentration to the amount of $\beta$-actin. (b), (c), (d), (e) the density of each band as determined using Alpha image software and expressed as a relative intensity against the $\beta$-actin band. From left to right, 1 , naïve; 2 , pcD/proV; 3, proV-IL9/pcD; 4, pcD-VP1/proV; 5, pcD-VP1/proV-IL9. 
TABLE 2: Target gene primers.

\begin{tabular}{ll}
\hline Target gene & Primers \\
\hline$\beta$-actin & $5^{\prime}$-TGACGGGGTCACCCACACTGTGCCCATCTA \\
& 3'-CTAGAAGCATTTGCGGTGGACGATGGAGGG \\
BCL-2 & $5^{\prime}$-GGCTACGAGTGGGATGCT \\
& $3^{\prime}$-GGGTCATGTGTGTGGAGAG \\
BCL-XL & $5^{\prime}$-CGATGAGTTTGAACTGCG \\
& $3^{\prime}$-CACCTAGAGCCTTGGATCC \\
BAX & 5'-CTGCAGAGGATGATTGCTGA \\
& $3^{\prime}$-CCAACATTGCATGGTGCTAC \\
BLF-1 & $5^{\prime}$-CAGGGAAGATGGCTGAGTCT \\
& $3^{\prime}$ - TTCTGCCGTATCCATTCTCC \\
\hline
\end{tabular}

was at the similar level with that of pcD-VP1 plus proV. It may indicate that IL-9 favorably induces the development of IFN- $\gamma$-producing $\mathrm{CD} 8^{+} \mathrm{T}$ cells (Tc1), not IL-17-producing $\mathrm{CD}^{+} \mathrm{T}$ cells $(\mathrm{Tc} 17)$.

3.5. IL-9 Enhanced Antiapoptotic Gene Expression in $C D 8^{+}$ $T$ Cells. Since IL-9 could affect on apoptosis [18], we examined the effect of IL-9 as adjuvant on Antiapoptotic and proapoptotic gene expressions in $\mathrm{CD} 8^{+} \mathrm{T}$ cells on day 7 after the third immunization. As depicted in Figure 5, the levels of mRNAs for BCL-2 and BCL-XL induced by pcD-VP1 plus proV-IL9 were higher, whereas the levels of mRNAs for BLF1 and BAX were not affected among the groups, indicating that the IL-9 may enhance survival of activated $\mathrm{CD} 8^{+} \mathrm{T}$ cells via apoptotic mechanism.

\section{Discussion}

Our recent studies demonstrated that IL-9 as molecular adjuvant can induce strong humoral and cellular immune responses. Most importantly, a significant higher level of cytotoxic responses was observed in the mice immunized with pcD-VP1 plus proV-IL9. In addition, IFN- $\gamma$ and perforin were up-regulated in $\mathrm{CD} 8^{+} \mathrm{T}$ cells, suggesting that IFN- $\gamma$-producing $\mathrm{CD} 8^{+} \mathrm{T}$ cells $(\mathrm{Tc} 1)$ were mostly affected in the cytotoxic responses. This may be owned to high expression levels of anti-apoptosis genes of BCL-2 and BCL$\mathrm{XL}$ induced in $\mathrm{CD}^{+} \mathrm{T}$ cells by such adjuvant.

Immunization with DNA vaccine encoding an immunogenic antigen represents a novel and promising method in vaccine research and development. Many studies have demonstrated that the expressed antigen is naturally processed and presented to $\mathrm{T}$ cells, inducing a broad range of immune responses including antibody production and the activation of T cells [19-22]. However, plasmid DNA immunogenicity is relatively low compared to viral vectors; various strategies have been proposed to enhance it, such as molecular adjuvants.

IL-9 is a $14 \mathrm{kDa}$ cytokine and involved in immune responses to helminthes as well as allergy [23, 24], it is generally attributed to $\mathrm{T}_{\mathrm{H}} 2$ cells. To date, IL-9 seemed to be associated with the Treg and $\mathrm{T}_{\mathrm{H}} 17$ cells [25-27]. Two studies suggested that IL-9 expression in $\mathrm{T}_{\mathrm{H}} 9$ cells is distinct from other $\mathrm{CD}^{+} \mathrm{T}$ cell subsets $[28,29]$. Importantly, IL9 supports the growth of $\mathrm{T}$ cells and also increases the production of IgG1 and IgE in B lymphocytes. However, IL-9 or its expressing construct has not been tested directly to determine what particular immune responses could be affected if it is used as a molecular adjuvant. From this study, we observed that IL-9 as the molecular adjuvant could increase humoral and cell proliferative responses.

Antigen-specific CTL response plays a key role in the protection against viruses or other intracellular pathogens. IFN- $\gamma$-producing $\mathrm{CD} 8^{+} \mathrm{T}$ cells $(\mathrm{Tc} 1)$ and IL-17-producing $\mathrm{CD} 8^{+} \mathrm{T}$ cells $(\mathrm{Tc} 17)$ can enhance cytotoxic responses. Tc17 cells, a unique subset of $\mathrm{CD} 8^{+} \mathrm{T}$ cells, were found in the lung following primary challenge with influenza $\mathrm{A}$ and protected against lethal influenza challenge $[30,31]$. Cytotoxicity can be induced by two distinct molecular pathways: upregulation of perforin, or up-regulation of FasL (CD95L) $[32,33]$. In our study, we found that high level expressions of IFN- $\gamma$ and perforin were observed to associate with CD8 ${ }^{+}$ $\mathrm{T}$ cells, not the IL-17. This indicates that the IL-9-induced Tc1, but not the Tc17, enhances cytotoxic responses through up-regulation of perforin.

In sum, our results show for the first time that FMDV DNA vaccine combined with IL-9 expressing plasmid can induce strong immune responses and enhanced Tcl mediated cytotoxic responses. This IL-9 may be served as a promising molecular adjuvant for DNA vaccinations.

\section{Acknowledgments}

This work was supported in part by National Key Technology R\&D Program of China (2004BA519A39 and 2006BAD06A06), National Nature Science Foundation (30771602), and National Mega Grand Program on Key Infectious Diseases of China (2008ZX10001-012) to BW. The authors would also like to thank Dr. Jane QL Yu and Zhonghuai He for their technical assistance.

\section{References}

[1] M. J. Grubman and B. Baxt, "Foot-and-mouth disease," Clinical Microbiology Reviews, vol. 17, no. 2, pp. 465-493, 2004.

[2] J. W. McVicar and P. Sutmoller, "The epizootiological importance of foot-and-mouth disease carriers-II. The carrier status of cattle exposed to foot-and-mouth disease following vaccination with an oil adjuvant inactivated virus vaccine," Archiv für die Gesamte Virusforschung, vol. 26, no. 3, pp. 217224, 1969.

[3] J. Chinsangaram, C. Beard, P. W. Mason, M. K. Zellner, G. Ward, and M. J. Grubman, "Antibody response in mice inoculated with DNA expressing foot-and-mouth disease virus capsid proteins," Journal of Virology, vol. 72, no. 5, pp. 4454-4457, 1998.

[4] D. J. Shedlock and D. B. Weiner, "DNA vaccination: antigen presentation and the induction of immunity," Journal of Leukocyte Biology, vol. 68, no. 6, pp. 793-806, 2000.

[5] G. Ward, E. Rieder, and P. W. Mason, "Plasmid DNA encoding replicating foot-and-mouth disease virus genomes induces 
antiviral immune responses in swine," Journal of Virology, vol. 71, no. 10, pp. 7442-7447, 1997.

[6] S. Gurunathan, D. M. Klinman, and R. A. Seder, "DNA vaccines: immunology, application, and optimization," Annual Review of Immunology, vol. 18, pp. 927-974, 2000.

[7] C. Svanholm, B. Lowenadler, and H. Wigzell, "Amplification of T-cell and antibody responses in DNA-based immunization with HIV-1 Nef by co-injection with a GM-CSF expression vector," Scandinavian Journal of Immunology, vol. 46, no. 3, pp. 298-303, 1997.

[8] J. J. Kim, H. C. Maguire Jr., L. K. Nottingham, et al., "Coadministration of IL-12 or IL-10 expression cassettes drives immune responses toward a Th1 phenotype," Journal of Interferon and Cytokine Research, vol. 18, no. 7, pp. 537-547, 1998.

[9] J.-C. Renauld, F. Houssiau, J. Louahed, A. Vink, J. Van Snick, and C. Uyttenhove, "Interleukin-9," Advances in Immunology, vol. 54, pp. 79-97, 1993.

[10] C. Uyttenhove, R. J. Simpson, and J. Van Snick, "Functional and structural characterization of P40, a mouse glycoprotein with T-cell growth factor activity," Proceedings of the National Academy of Sciences of the United States of America, vol. 85, no. 18, pp. 6934-6938, 1988.

[11] C. Petit-Frere, B. Dugas, P. Braquet, and J. M. Mencia-Huerta, "Interleukin-9 potentiates the interleukin-4-induced IgE and IgG1 release from murine B lymphocytes," Immunology, vol. 79, no. 1, pp. 146-151, 1993.

[12] M. D. Leech and R. K. Grencis, "Induction of enhanced immunity to intestinal nematodes using IL-9-producing dendritic cells," Journal of Immunology, vol. 176, no. 4, pp. 2505-2511, 2006.

[13] H. Jin, Y. Li, Z. Ma, et al., "Effect of chemical adjuvants on DNA vaccination," Vaccine, vol. 22, no. 21-22, pp. 2925-2935, 2004.

[14] X. Du, G. Zheng, H. Jin, et al., "The adjuvant effects of costimulatory molecules on cellular and memory resposes to HBsAg DNA vaccination," Journal of Gene Medicine, vol. 9, no. 2, pp. 136-146, 2007.

[15] G. Zhao, H. Jin, J. Li, et al., "PyNTTTTGT prototype oligonucleotide IMT504, a novel effective adjuvant of the FMDV DNA vaccine," Viral Immunology, vol. 22, no. 2, pp. 131-138, 2009.

[16] K.-D. Park, L. Marti, J. Kurtzberg, and P. Szabolcs, "In vitro priming and expansion of cytomegalovirus-specific Th1 and Tc1 T cells from naive cord blood lymphocytes," Blood, vol. 108, no. 5, pp. 1770-1773, 2006.

[17] C. Ortega, A. S. Fernandez, J. M. Carrillo, et al., "IL-17producing $\mathrm{CD}^{+} \mathrm{T}$ lymphocytes from psoriasis skin plaques are cytotoxic effector cells that secrete Th17-related cytokines," Journal of Leukocyte Biology, vol. 86, no. 2, pp. 435-443, 2009.

[18] J.-B. Demoulin, E. van Roost, M. Stevens, B. Groner, and J.C. Renauld, "Distinct roles for STAT1, STAT3, and STAT5 in differentiation gene induction and apoptosis inhibition by interleukin-9," The Journal of Biological Chemistry, vol. 274, no. 36, pp. 25855-25861, 1999.

[19] B. Wang, K. E. Ugen, V. Srikantan, et al., "Gene inoculation generates immune responses against human immunodeficiency virus type 1," Proceedings of the National Academy of Sciences of the United States of America, vol. 90, no. 9, pp. 41564160, 1993.

[20] J. B. Ulmer, J. J. Donnelly, S. E. Parker, et al., "Heterologous protection against influenza by injection of DNA encoding a viral protein," Science, vol. 259, no. 5102, pp. 1745-1749, 1993.
[21] J. J. Donnelly, J. B. Ulmer, J. W. Shiver, and M. A. Liu, "DNA vaccines," Annual Review of Immunology, vol. 15, pp. 617-648, 1997.

[22] D. M. Feltquate, S. Heaney, R. G. Webster, and H. L. Robinson, "Different T helper cell types and antibody isotypes generated by saline and gene gun DNA immunization," Journal of Immunology, vol. 158, no. 5, pp. 2278-2284, 1997.

[23] H. Faulkner, J.-C. Renauld, J. van Snick, and R. K. Grencis, "Interleukin-9 enhances resistance to the intestinal nematode Trichuds muris," Infection and Immunity, vol. 66, no. 8, pp. 3832-3840, 1998.

[24] A. Soussi-Gounni, M. Kontolemos, and Q. Hamid, "Role of IL-9 in the pathophysiology of allergic diseases," Journal of Allergy and Clinical Immunology, vol. 107, no. 4, pp. 575-582, 2001.

[25] L.-F. Lu, E. F. Lind, D. C. Gondek, et al., "Mast cells are essential intermediaries in regulatory T-cell tolerance," Nature, vol. 442, no. 7106, pp. 997-1002, 2006.

[26] W. Elyaman, E. M. Bradshaw, C. Uyttenhove, et al., "IL-9 induces differentiation of $\mathrm{T}_{\mathrm{H}} 17$ cells and enhances function of FoxP3+ natural regulatory T cells," Proceedings of the National Academy of Sciences of the United States of America, vol. 106, no. 31, pp. 12885-12890, 2009.

[27] E. C. Nowak, C. T. Weaver, H. Turner, et al., "IL-9 as a mediator of Th17-driven inflammatory disease," Journal of Experimental Medicine, vol. 206, no. 8, pp. 1653-1660, 2009.

[28] V. Dardalhon, A. Awasthi, H. Kwon, et al., "IL-4 inhibits TGF$\beta$-induced Foxp $3^{+}$T cells and, together with TGF- $\beta$, generates IL-9+ IL-10 ${ }^{+}$Foxp3- effector T cells," Nature Immunology, vol. 9, no. 12, pp. 1347-1355, 2008.

[29] M. Veldhoen, C. Uyttenhove, J. van Snick, et al., "Transforming growth factor- $\beta$ 'reprograms' the differentiation of $\mathrm{T}$ helper 2 cells and promotes an interleukin 9-producing subset," Nature Immunology, vol. 9, no. 12, pp. 1341-1346, 2008.

[30] H. R. Yen, T. J. Harris, S. Wada, et al., "Tc17 CD8 T cells: functional plasticity and subset diversity," Journal of Immunology, vol. 183, no. 11, pp. 7161-7168, 2009.

[31] H. Hamada, M. L. Garcia-Hernandez, J. B. Reome, et al., "Tc17, a unique subset of CD8 T cells that can protect against lethal influenza challenge," Journal of Immunology, vol. 182, no. 6, pp. 3469-3481, 2009.

[32] J.-H. Li, D. Rosen, D. Ronen, et al., "The regulation of CD95 ligand expression and function in CTL," Journal of Immunology, vol. 161, no. 8, pp. 3943-3949, 1998.

[33] M. Hayashida, H. Kawano, T. Nakano, K. Shiraki, and A. Suzuki, "Cell death induction by CTL: perforin/granzyme B system dominantly acts for cell death induction in human hepatocellular carcinoma cells," Proceedings of the Society for Experimental Biology and Medicine, vol. 225, no. 2, pp. 143150, 2000. 


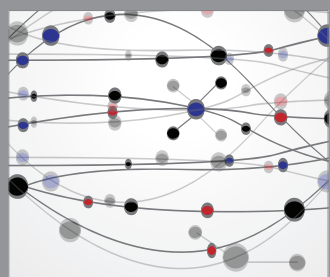

The Scientific World Journal
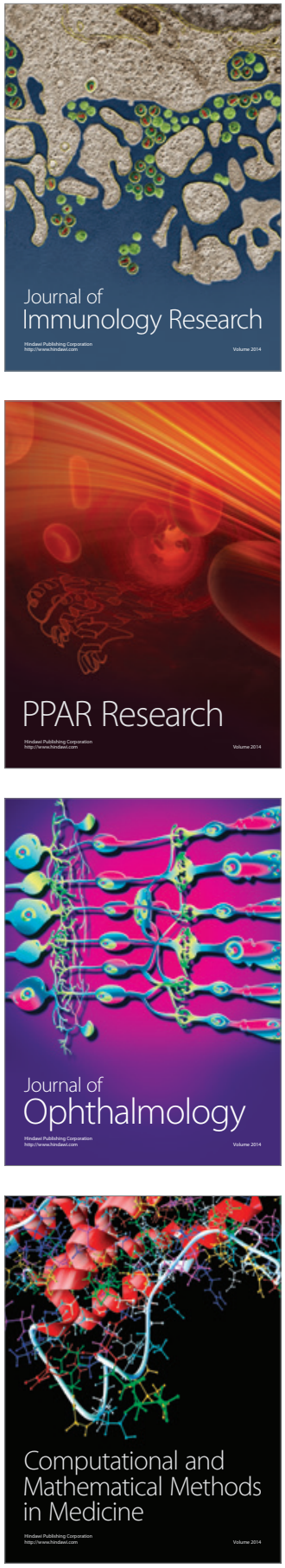

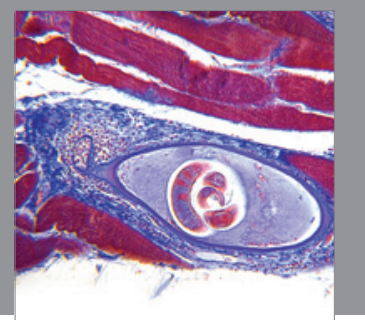

Gastroenterology

Research and Practice
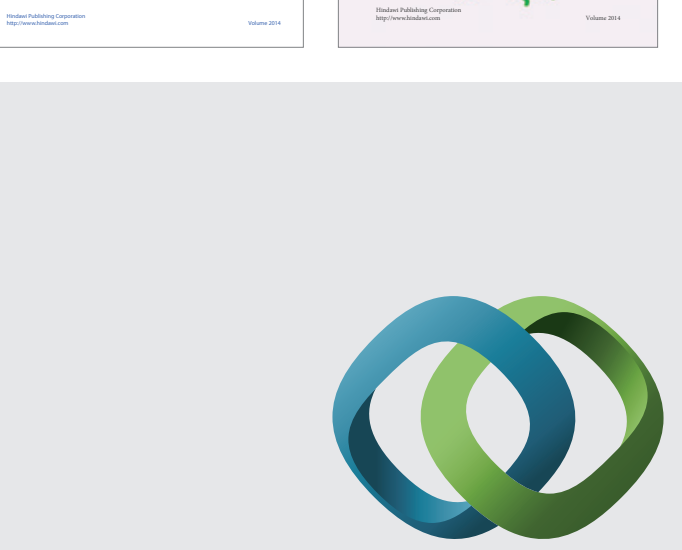

\section{Hindawi}

Submit your manuscripts at

http://www.hindawi.com
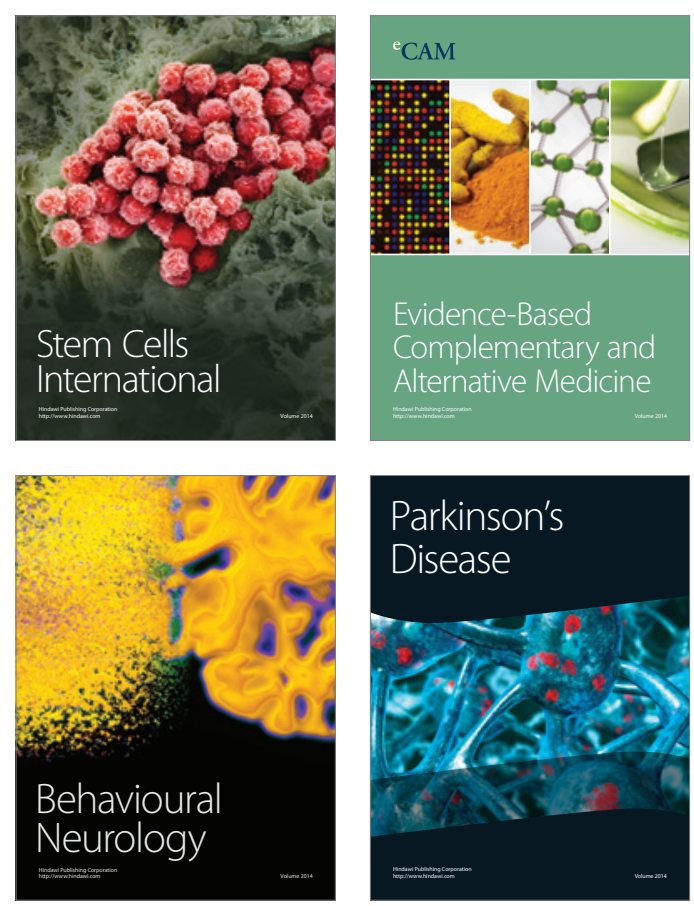

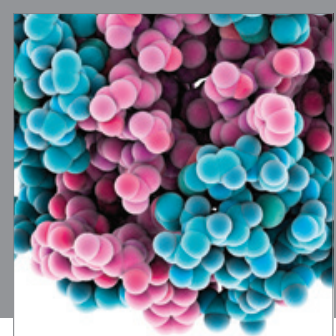

Journal of
Diabetes Research

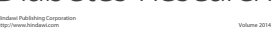

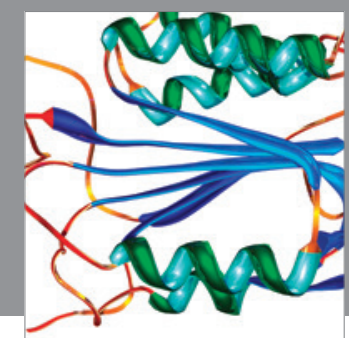

Disease Markers
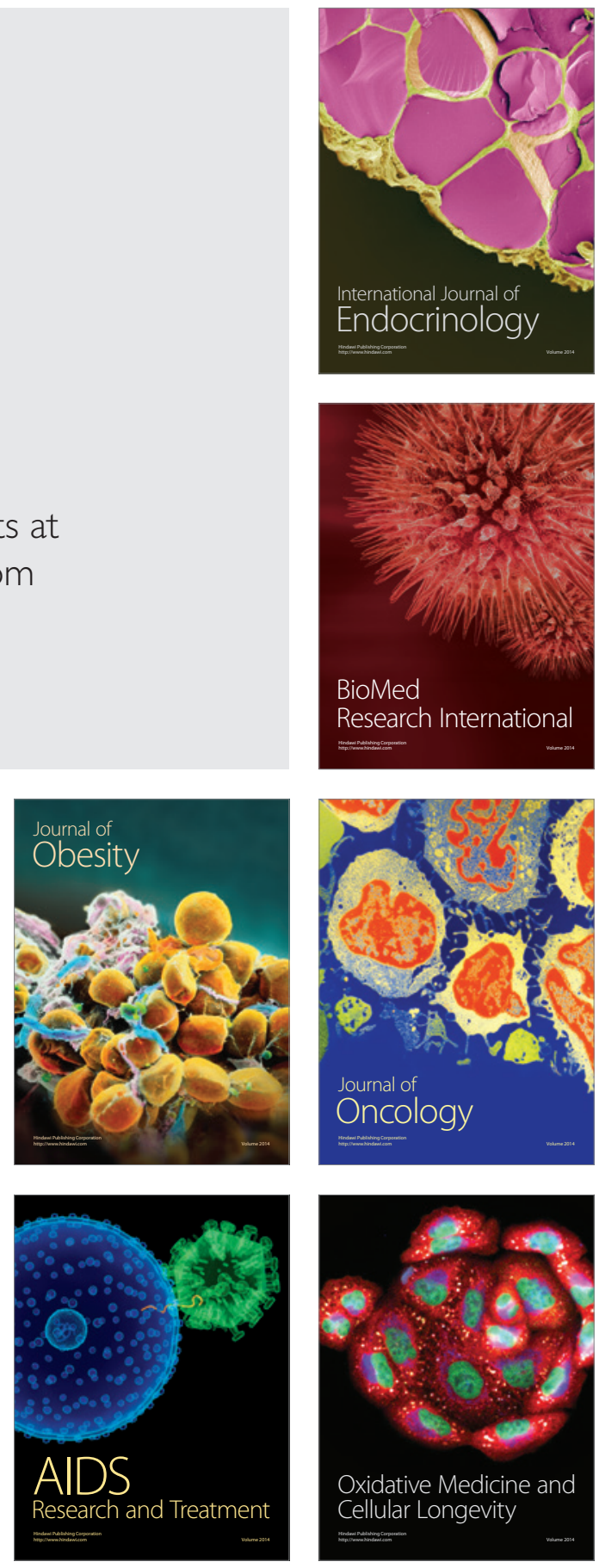